\title{
Helicobacter pylori non-cytotoxic genotype enhances mucosal gastrin and mast cell tryptase
}

\author{
D Basso, F Navaglia, L Brigato, F Di Mario, M Rugge, M Plebani
}

\begin{abstract}
Aims-To determine the association, if any, between $H$ pylori genotype and the gastric mucosal variations in the levels of gastrin, somatostatin, tryptase, and histamine.

Methods-49 patients affected by duodenal ulcer and 48 by non-ulcer dyspepsia were studied. To identify the $H$ pylori genotype, the presence of the cagA gene and vacA alleles $\mathrm{m} 1, \mathrm{~m} 2, \mathrm{~s} 1$, and $\mathrm{s} 2$ were analysed by polymerase chain reaction. Gastrin, somatostatin, tryptase, and histamine were measured in antral mucosal biopsies.

Results-57 patients were infected with $H$ pylori (30 with duodenal ulcer and 27 with non-ulcer dyspepsia). Gastrin and tryptase were increased in patients with $H$ pylori infection, although the variations were statistically significant only for gastrin; somatostatin and histamine were not influenced by $H$ pylori infection. In patients with non-ulcer dyspepsia the absence of the cagA gene and the presence of vacA alleles $\mathrm{s} 2$ and $\mathrm{m} 2$ were associated with higher values of tryptase and to a lesser extent of gastrin. These associations were not found in patients with duodenal ulcer.
\end{abstract}

Conclusions-The cagA negative $\mathrm{s} 2 \mathrm{~m} 2$ strain of $H$ pylori may be less dangerous for the gastric mucosa than other $\boldsymbol{H}$ pylori strains since it enhances tryptase production by gastric mucosal mast cells; this enzyme is thought to stimulate tissue turnover and favour wound healing. (f Clin Pathol 1999;52:210-214)

Keywords: Helicobacter pylori; mast cells; tryptase; gastrin

The Gram negative bacterium Helicobacter pylori colonises the gastric mucosa, at the antrum in particular. H pylori infection has several sequelae, including antral gastritis, chronic atrophic gastritis, gastric and duodenal ulcer, gastric adenocarcinoma, and MALToma. ${ }^{1-4}$ This wide spectrum of diseases from the same microorganism may depend on differences in the host response, but also on differences between the strains of $H$ pylori causing infection..$^{5-8}$ Two types of $H$ pylori have been described: type I produces a vacuolating cytotoxin which plays a fundamental role in H pylori pathogenicity. ${ }^{5-11}$ This cytotoxin is not produced by type II strains. The cagA gene is also often found in type I strains. ${ }^{12}$ Encoding a highly immunogenic protein, this gene, almost completely absent in type II strains, is considered to be a marker of $H$ pylori aggres- siveness and is located inside a pathogenicity island of Hpylori, which encodes specific virulence factors. ${ }^{13}$

$H$ pylori infection results in a cascade of biochemical events in the gastric mucosa, including enhanced gastrin release after a meal caused by reduced somatostatin production. ${ }^{14-17}$ In addition, microscopic mucosal inflammation characterised by infiltration with mononuclear and polymorphonuclear leucocytes is found in most H pylori infected patients. ${ }^{18}{ }^{19}$ Gastric mucosal inflammation associated with $H$ pylori infection is mediated by release of cytokines, which is greater when the infecting strain is cagA positive. ${ }^{40-24}$

In the inflammatory process, mast cells play a pivotal role as initiators and regulators of inflammation. ${ }^{25}$ Found in relatively large numbers next to blood and lymphatic vessels, mast cells are most prominent immediately beneath the epithelial surfaces of the skin and the mucosae of the respiratory, genitourinary, and gastrointestinal tracts. ${ }^{25}$ As they play a key role in infection and immunity and are present in large numbers (about $20000 / \mathrm{mm}^{3}$ ) in the mucosa of the gastrointestinal tract, it is likely that mast cells participate in the pathophysiology of $H$ pylori associated gastroduodenal diseases. In particular, $H$ pylori downregulates histamine release from mast cells isolated from rat peritoneum ${ }^{26}$; water extracts of $\mathrm{H}$ pylori cause rat mesentery mast cells to degranulate ${ }^{27}$; and in patients with $H$ pylori infection, the density of gastric mucosal mast cells is increased. $^{28}$

As no data are available on the different effects of $H$ pylori strains on gastric mast cells, our aims in this study were to determine whether there is an association between the $H$ pylori genotype and the function of gastric mucosal D, G, and mast cells, and to verify whether $H$ pylor $i$ induced gastritis may play any role in this context.

\section{Methods}

We studied 97 patients ( 52 males, 45 females, age range 17 to 79 years). The diagnoses, made on the basis of endoscopic and microscopic findings and taking into account the clinical history of each patient, were duodenal ulcer $(n=49)$ and non-ulcer dyspepsia $(n=48)$. All the patients underwent upper gastrointestinal endoscopy, during which samples of gastric juice and six antral and two body biopsies were obtained. Two of the antral and one body biopsy were used for the histological evaluation (haematoxylin and eosin staining); two further antral biopsies and the remaining body biopsy were used for the histological assessment of
Accepted for publication 19 October 1998 
Table 1 Comparison of histological scores for patients with duodenal ulcer or non-ulcer dyspepsia

\begin{tabular}{|c|c|c|c|c|c|c|}
\hline & \multicolumn{3}{|c|}{ Antrum } & \multicolumn{3}{|c|}{ Body } \\
\hline & $C I$ & $P M N$ & $H p$ & $C I$ & $P M N$ & $H p$ \\
\hline \multicolumn{7}{|c|}{ H pylori positive patients } \\
\hline \multicolumn{7}{|c|}{ Non-ulcer dyspepsia } \\
\hline Range & $0-3$ & $1-3$ & $1-3$ & $0-3$ & $0-3$ & $1-3$ \\
\hline Median & 2.0 & 1.5 & 2.0 & 2.0 & 1.0 & 2.0 \\
\hline \multicolumn{7}{|c|}{ Duodenal ulcer } \\
\hline Range & $1-3$ & $1-3$ & $1-3$ & $0-2$ & $0-3$ & $1-3$ \\
\hline Median & 2.0 & 2.0 & 2.0 & 2.0 & 1.0 & 2.0 \\
\hline \multicolumn{7}{|c|}{ H pylori negative patients } \\
\hline \multicolumn{7}{|c|}{ Non-ulcer dyspepsia } \\
\hline Range & $0-2$ & 0 & 0 & $0-1$ & 0 & 0 \\
\hline Median & 1.0 & 0 & 0 & 1.0 & 0 & 0 \\
\hline \multicolumn{7}{|c|}{ Duodenal ulcer } \\
\hline Range & $1-3$ & 0 & 0 & $0-2$ & 0 & 0 \\
\hline Median & 1.0 & 0 & 0 & 2.0 & 0 & 0 \\
\hline
\end{tabular}

CI, chronic inflammation; Hp, H pylori colonisation density; PMN, polymorphonuclear cell infiltrate.
H pylori infection (Giemsa and/or WartinStarry staining); the gastric juice sample was used for $\mathrm{pH}$ measurement (Crison $\mathrm{pHmeter}$ ) and for the polymerase chain reaction (PCR); the remaining two antral biopsies were used for histamine, somatostatin, gastrin, and tryptase determinations.

Immediately after sampling, the latter two specimens, were transferred to a test tube containing hexane and cooled to $-70^{\circ} \mathrm{C}$ in a solid $\mathrm{CO}_{2}$ acetone bath and then stored at $-20^{\circ} \mathrm{C}$ until homogenised using a technique described elsewhere ${ }^{29}$ For both antral and body biopsies the following features were evaluated and graded according to the updated Sydney system $^{30}$ : atrophy, chronic inflammation, polymorphonuclear cell activity (neutrophil infiltration), and $H$ pylori colonisation density. DNA was extracted from gastric juice. ${ }^{31}$ We then amplified the following $H$ pylori genes by PCR: urease A (ureA), cagA, and vacA polymorphism under previously described conditions. $^{32}$ In mucosal homogenates we measured the following: (1) total protein content by Bradford's method, ${ }^{33}$ using reagents from Bio-Rad Laboratories; (2) tryptase, using a solid phase immunoradiometric assay (Kabi Pharmacia Tryptase Riact); (3) gastrin, histamine, and somatostatin by radioimmunoassay (Sorin Biomedica; Pharmacia; and EuroDiagnostica, respectively). The results for tryptase, gastrin, histamine, and somatostatin were referred to the protein concentration.

STATISTICS

Statistical analysis of the data was made using analysis of variance (ANOvA one way), Bonferroni's test for pairwise comparisons, the
Kruskal-Wallis test, the Mann-Whitney U test, linear regression analysis, and Spearman's regression analysis.

\section{Results}

H PYLORI INFECTION AND GASTRITIS

The histological assessment of $H$ pylori and ureA positivity in gastric juice by PCR gave overlapping results. With both procedures, $H$ pylori infection was found in 57 cases (30 duodenal ulcer and 27 non-ulcer dyspepsia), the remaining 40 patients being $H$ pylori negative. Of these, 32 (16 of 19 duodenal ulcer and 16 of 21 non-ulcer dyspepsia) had been treated for $H$ pylori infection at least three months before the study.

The frequency of antral mucosal atrophy did not differ between $H$ pylori positive and $H$ pylori negative patients with duodenal ulcer or non-ulcer dyspepsia $\left(\chi^{2}=4.55, \mathrm{NS}\right)$.

Table 1 shows the histological scores found in the antrum and the body for $H$ pylori positive or negative patients with duodenal ulcer or non-ulcer dyspepsia. Chronic inflammation in the antrum was more severe in $H$ pylori positive than in $H$ pylori negative patients; when $H$ pylori positive and $H$ pylori negative patients were considered separately, higher grades of antral inflammation were found in duodenal ulcer patients than in patients with non-ulcer dyspepsia (Kruskal-Wallis $\mathrm{H}=4.52, \mathrm{p}<0.05$ for $H$ pylori positive and $\mathrm{H}=6.51, \mathrm{p}<0.05$ for $H$ pylori negative).

Chronic inflammation in the body of the stomach more severe in $H$ pylori positive patients than in $H$ pylori negative patients $(\mathrm{H}=$ 51.38, $\mathrm{p}<0.001$ ), but no differences between duodenal ulcer and non-ulcer dyspepsia were found $(\mathrm{H}=1.88$, NS for $H$ pylori positive and $\mathrm{H}=0.11$, NS for $H$ pylori negative).

In $H$ pylori positive patients, polymorphonuclear infiltration in the antrum was more pronounced in duodenal ulcer than in nonulcer dyspepsia $(H=5.09, p<0.05)$. This was not the case for the body of the stomach $(\mathrm{H}=0.44, \mathrm{NS})$.

No differences between duodenal ulcer and non-ulcer dyspepsia patients were found in relation to $H$ pylori colonisation density, either in the antrum or in the body $(\mathrm{H}=2.13$, NS, and $\mathrm{H}=0.47, \mathrm{NS}$ ). The grade of both the antral and the body polymorphonuclear infiltrate was correlated with the corresponding $H$ pylori density (Spearman's $r=0.397$, $\mathrm{p}<0.001$, and $r=0.750, \mathrm{p}<0.001)$.

The cagA gene was positive in 39 cases, which included 24 of the $30 \mathrm{H}$ pylori positive patients

Table 2 Antral tryptase, gastrin, histamine, and somatostatin (SMS) in the patients studied

\begin{tabular}{|c|c|c|c|c|c|c|c|c|}
\hline \multirow[b]{2}{*}{ Diagnosis } & \multicolumn{2}{|c|}{ Tryptase (U/g) } & \multicolumn{2}{|c|}{ Gastrin $(\mu g / g)$} & \multicolumn{2}{|c|}{ Histamine $(\mu g / g)$} & \multicolumn{2}{|c|}{$S M S(\mu g / g)$} \\
\hline & Mean & SEM & Mean & SEM & Mean & SEM & Mean & SEM \\
\hline DU Hp pos $(n=30)$ & 104 & 14 & 12 & 1.5 & 21 & 7.3 & 925 & 113 \\
\hline DU Hp neg $(n=19)$ & 121 & 20 & 12 & 1.9 & 24 & 7.5 & 914 & 89 \\
\hline NUD Hp pos $(n=27)$ & 155 & 16 & $25^{\star}$ & 3.1 & 28 & 7.1 & 934 & 64 \\
\hline NUD $\mathrm{Hp}$ neg $(\mathrm{n}=21)$ & 125 & 15 & 14 & 3.1 & 51 & 12.3 & 1044 & 110 \\
\hline ANOVA, one way & \multicolumn{2}{|c|}{$\begin{array}{c}\mathrm{F}=2.07 \\
\mathrm{NS}\end{array}$} & \multicolumn{2}{|c|}{$\begin{array}{c}F=6.38 \\
p<0.001\end{array}$} & \multicolumn{2}{|c|}{$\begin{array}{c}\mathrm{F}=2.24 \\
\mathrm{NS}\end{array}$} & \multicolumn{2}{|c|}{$\begin{array}{c}\mathrm{F}=0.33 \\
\mathrm{NS}\end{array}$} \\
\hline
\end{tabular}

DU, duodenal ulcer; Hp, H pylori; neg, negative; pos, positive; NUD, non-ulcer dyspepsia. 

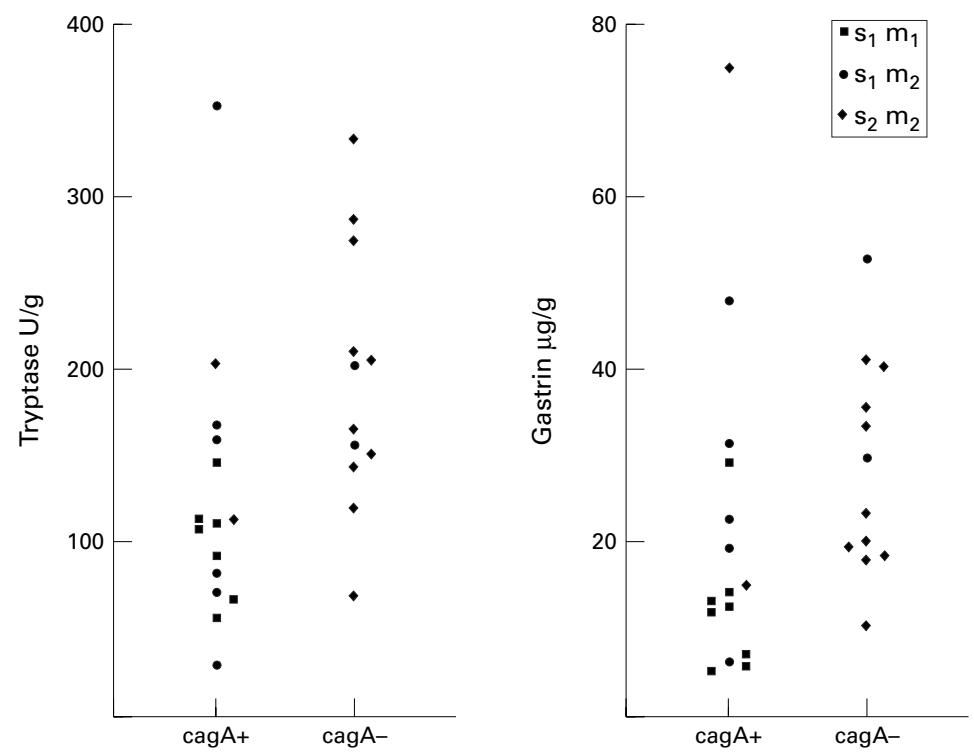

Figure 1 Individual values of mucosal tryptase and gastrin in $H$ pylori positive patients with non-ulcer dyspepsia subdivided on the basis of cagA positive (cag $A+)$ or negative $(\mathrm{cag} A-)$ findings. For each patient the results for vacA alleles are also reported.

with duodenal ulcer and 15 of the 27 with nonulcer dyspepsia. Alleles $\mathrm{s} 1$ and $\mathrm{m} 1$ were found in 37 of 39 and in 28 of 39 cagA positive patients, and in seven of 18 and two of 18 cagA negative patients. The cagA gene and the $\mathrm{ml}$ allele of vacA were significantly associated with a higher grade of polymorphonuclear cell infiltration of both the antrum (Mann-Whitney $U$ test: $\mathrm{z}=1.82, \mathrm{p}<0.05$ and $\mathrm{z}=2.47, \mathrm{p}<0.01)$ and the body $(\mathrm{z}=3.28, \mathrm{p}<0.001$ and $\mathrm{z}=2.16$, $\mathrm{p}<0.05)$. The s1 allele of vacA was associated with a higher degree of polymorphonuclear cell infiltration ( $\mathrm{z}=2.39, \mathrm{p}<0.01)$ and inflammation $(z=1.82, p<0.05)$ in the antrum but not in the body.

H PYLORI, TRYPTASE, GASTRIN, SOMATOSTATIN, HISTAMINE, AND pH

Table 2 shows mean values, standard errors of the mean, and a statistical analysis of tryptase, gastrin, histamine, and somatostatin mucosal concentrations in the patients studied.

Gastric juice pH (mean (SEM)) was significantly higher in $H$ pylori infected than in $H$ pylori non infected patients, at $3.04(0.33) v 1.91$ (0.22) (Student's $t$ test: $t=2.77, \mathrm{p}<0.01$ ). Gastric juice $\mathrm{pH}$ correlated with the grade of polymorphonuclear cell infiltration in the body (Spearman's $r=0.248, \mathrm{p}<0.05$ ) but not in the antrum (Spearman's $r=0.211, \mathrm{NS}$ ).

There was a positive correlation between mucosal tryptase and gastrin values $(r=0.290$, $\mathrm{p}<0.01)$; mucosal gastrin was also correlated with gastric juice $\mathrm{pH}$ values $(r=0.456$, $\mathrm{p}<0.001)$. None of the mucosal indices evaluated was correlated with the grade of gastritis or with the grade of polymorphonuclear cell infiltrate of the antrum or the body.

cagA, vacA, TRYPTASE, GASTRIN, SOMATOSTATIN, AND HISTAMINE

The individual data for tryptase and gastrin in patients with non-ulcer dyspepsia subdivided on the basis of the presence or absence of cagA are shown in fig 1 , together with data on vacA polymorphism for each subject. The mean levels of tryptase were significantly higher in patients with the cagA negative genotype (Student's $t$ test: $t=2.30, \mathrm{p}<0.05)$, or who were positive for the $\mathrm{S} 2(t=2.05, \mathrm{p}<0.05)$ or M2 alleles $(t=2.90, \mathrm{p}<0.01)$ of vacA. A similar pattern was observed for mucosal gastrin, although significant differences were found only in relation to the M1 and M2 alleles of $\operatorname{vacA}(t=3.62, \mathrm{p}<0.01)$.

Mucosal somatostatin and histamine values were not influenced by cagA or by the vacA genotype.

\section{Discussion}

We have confirmed here that gastric histology and the polymerase chain reaction give overlapping results in diagnosing $H$ pylori infection. ${ }^{31}$ Also, and in agreement with previous findings by Warburton et al, ${ }^{19}$ we found that the infection was localised to the antrum and the body of the stomach, and $H$ pylori colonisation density was directly correlated with the degree of polymorphonuclear cell infiltration. In $H$ pylori positive patients, the degree of chronic inflammation and polymorphonuclear infiltration involving the gastric body was slightly more severe in patients with duodenal ulcer than in those with non-ulcer dyspepsia, in contrast to the findings of Warburton et al. ${ }^{19}$

It is now clear that the $H$ pylori species is heterogeneous, comprising different strains. We typed the genome of the infecting strain of $H$ pylori in our patients by defining cagA and vacA status. As in previous studies, ${ }^{6-8} 32$ patients with duodenal ulcer were infected mainly by cagA positive $H$ pylori strains possessing the $\mathrm{s} 1$ and $\mathrm{m} 1$ alleles of vacA (type I), while the cagA gene was present in about half of the patients with non-ulcer dyspepsia. In agreement with Warburton et al, ${ }^{19}$ we observed that infections caused by cagA positive, vacA s $1 \mathrm{~m} 1$ strains tended to be associated with a major degree of polymorphonuclear cell infiltration of the gastric mucosa.

H pylori associated chronic mucosal inflammation might alter normal gastric physiology, and in particular peptic acid secretion, either directly or through alterations to cells involved in the regulation of the gastric secretory process, such as antral G or D cells, enterochromaffinlike (ECL) cells, and mast cells. Mast cells play a crucial role in the pathophysiology of several chronic gastrointestinal inflammatory conditions. ${ }^{25}$ To investigate the influence of $H$ pylori on mast cells, we measured the mucosal levels of tryptase and histamine. In human gastric mucosa the former is present in mast cells only, ${ }^{34}$ while the latter originates both from mast cells and ECL cells. ${ }^{35}$ We found no significant differences in mucosal tryptase and histamine levels between the groups studied. These preliminary findings suggest that $H$ pylori infection does not affect the function of mast cells. However, in patients with non-ulcer dyspepsia, tryptase levels tended to be somewhat higher than in patients with other causes of gastric inflammation. To clarify this finding we focused our attention on gastrin, since in our previous papers we showed the presence of a gastrin- 
tryptase link. ${ }^{34} 36$ This was confirmed in the present study. Furthermore, mucosal gastrin levels were significantly higher in $H$ pylori positive patients with non-ulcer dyspepsia than in all other patient groups. These findings confirm recent data from Gillen et al showing that $H$ pylori seems to influence gastrin levels mainly in non-ulcer dyspepsia patients since it reduces their sensitivity to gastrin more than in patients with duodenal ulcer. ${ }^{37}$

The mechanism whereby $H$ pylori influences gastrin is not clear, although it has been suggested that it promotes enhanced gastrin release by reducing somatostatin production. ${ }^{15-17}$ To verify this, we measured mucosal levels of somatostatin in our material, but we found no correlation with $H$ pylori infection, nor was somatostatin correlated with gastrin. The discrepancy between these results and those published previously ${ }^{15-17}$ may depend upon the different approaches used to measure somatostatin: Moss et $a l^{15}$ and Graham et $a l^{16}$ measured somatostatin mRNA and the number of antral D cells, respectively, while we evaluated somatostatin concentration. Haruma et $a l,{ }^{17}$ who also evaluated the mucosal concentration of somatostatin, found low levels of this hormone in $H$ pylori positive patients, but the numbers were very small (six cases). We hypothesised that $H$ pylori may affect the function of antral $\mathrm{G}$ cells directly or indirectly, through mucosal inflammation or by enhancing gastric juice $\mathrm{pH}$, or both. Chronic mucosal inflammation, either of the antrum or of the body, was not related to mucosal gastrin or somatostatin levels, but gastric body polymorphonuclear infiltration was correlated with gastric juice $\mathrm{pH}$. This was higher in $H$ pylori positive patients with nonulcer dyspepsia and was correlated with mucosal gastrin. This suggests that the involvement of the gastric body by $H$ pylori infection in patients with non-ulcer dyspepsia may impair gastric acid secretion, leading to hypergastrinaemia.

We then ascertained whether the $H$ pylori genotype may influence mucosal levels of tryptase, gastrin, histamine, or somatostatin. In patients with duodenal ulcer no significant variations in these were found, and cagA positive $\mathrm{s} 1 \mathrm{~m} 1 \mathrm{H}$ pylori strains played a major role in causing the infection. Therefore, as expected, no significant association between these variables was found. On the other hand, in patients with non-ulcer dyspepsia, the higher levels of mucosal tryptase were associated with the $\mathrm{s} 2$ or $\mathrm{m} 2$ alleles of vacA and with cagA negative strains of $H$ pylori. In these patients, higher levels of mucosal gastrin were associated with the $\mathrm{m} 2$ allele of vacA, while histamine and somatostatin were not influenced by $H$ pylori strains. These findings are surprising - in non-ulcer dyspepsia the infection sustained by less virulent $H$ pylori strains causes increased production of tryptase by mast cells, possibly through gastrin stimulation. These data might be interpreted in the light of the role of tryptase in wound healing: this mast cell enzyme has been found to be a potent mitogen for epithelial cell proliferation, which is one of the final steps in the healing process. ${ }^{25} 38$ $H$ pylori infection sustained by type II strains may cause less gastric damage than type I strains, since the former may not only cause less extensive epithelial cell damage, but may also favour the defence mechanisms of the stomach against mucosal injury.

Filippo Navaglia is supported by a fellowship from the Associazione Italiana per la Ricerca sul Cancro.

1 Bayerdorffer E, Neubauer A, Rudolph B, et al. Regression of primary gastric lymphoma of mucosa-associated lymphoid tissue type after cure of Helicobacter pylori infection. Lancet 1995;345:1591-4

2 Calvert R, Randerson J, Evans P, et al. Genetic abnormalities during transition from Helicobacter-pylori-associated gastritis to low-grade MALToma. Lancet 1995;345:26-7.

3 McFarlane GA, Munro A. Helicobacter pylori and gastric cancer. Br F Surg 1997; 84:1190-9.

4 Peek RM, Blaser MJ. Pathophysiology of Helicobacter pylori-induced gastritis and peptic ulcer disease. Am $\mathcal{F} \mathrm{Med}$ 1997;102:200-7.

5 Blaser MJ. Helicobacter pylori phenotypes associated with peptic ulceration. Scand f Gastroenterol 1994;29(suppl 205): $1-5$

6 Atherton JC, Cao P, Peek RM, et al. Mosaicism in vacuolating cytotoxin alleles of Helicobacter pylori. Association of specific vacA types with cytotoxin production and peptic ulceration. F Biol Chem 1995;270:17771-7.

7 Cover TL. The vacuolating cytotoxin of Helicobacter pylori. Mol Microbiol 1996;20:241-6.

8 Atherton JC, Peek RM, Tham KT, et al. Clinical and pathological importance of heterogeneity in vacA, the vacuolating cytotoxin gene of Helicobacter pylori. Gastroenterology 1997;112:92-9.

9 Atherton JC. The clinical relevance of strain types of Helicobacter pylori. Gut 1997;40:701-3.

10 Phadnis SH, Ilver D, Janzon L, et al. Pathological significance and molecular characterization of the vacuolating toxin gene of Helicobacter pylori. Infect Immun 1994;62:1157-65.

11 Xiang Z, Censini S, Bayeli PF, et al. Analysis of expression of CagA and VacA virulence factors in 43 strains of
Helicobacter pylori reveals that clinical isolates can be divided into two major types and that CagA is not divided into two major types and that CagA is not Immun 1995;63:94-8.

12 Covacci A, Censini S, Bugnoli M, et al. Molecular characterization of the $128-\mathrm{kDa}$ immunodominant antigen of Helicobacter pylori associated with cytotoxicity and duodenal ulcer. Proc Natl Acad Sci USA 1993;90:5791-5.

13 Censini S, Lange C, Xiang Z, et al. cag, A pathogenicity island of Helicobacter pylori, encodes type I-specific and disease-associated virulence factors. Proc Natl Acad Sci USA 1996; 93:14648-53.

14 Graham DY, Opekun A, Lew GM, et al. Helicobacter pylori-associated exaggerated gastrin release in duodenal ulcer patients. Gastroenterology 1991;100:1571-5.

15 Moss SF, Legon S, Bishop AE, et al. Effect of Helicobacter pylori on gastric on gastrin somatostatin in duodenal ulcer pylori on gastric on gastrin som

16 Graham DY, Lew GM, Lechago J. Antral G-cell and D-cell numbers in Helicobacter pylori infection: effect of $\mathrm{H}$. pylori eradication. Gastroenterology 1993;104:1655-60.

17 Haruma K, Sumii K, Okamoto S, et al. Helicobacter pylori infection is associated with low antral somatostatin content in young adults. Scand $\mathcal{F}$ Gastroenterol 1995;30:550-3.

18 Plebani M, Basso D, Cassaro M, et al. Helicobacter pylori serology in patients with chronic gastritis. Am $\mathcal{F}$ Gastroenterol 1996;91:954-8.

19 Warburton VJ, Everett S, Mapstone NP, et al. Clinical and histological associations of cagA and vacA genotypes in Helicobacter pylori gastritis. F Clin Pathol 1998;51:55-61.

20 Crabtree JE, Farmery SM, Lindley IJD, et al. CagA/ cytotoxic strains of Helicobacter pylori and interleukin-8 in cytric

21 Gastric epithelial cell lines. F Clin Pathol 1994;47:945-50. interleukin-6 and -8 in Helicobacter pylori-positive dyspeptic patients. Am 7 Gastroenterol 1994;89:883-7.

22 Mostic SF, Legon S, Davies J, et al. Cytokine gene expression in Helicobacter pylori associated antral gastritis. Gut 1994; in Helicobacter

23 Crowe SE, Alvarez L, Dytoc M, et al. Expression of interleukin 8 and $\mathrm{CD} 54$ by human gastric epithelium after Helicobacter pylori infection in vitro. Gastroenterology 1995;108:65-74

24 Basso D, Scrigner M, Toma A, et al. Helicobacter pylori infection enhances mucosal interleukin-1 beta, interleukin-6, and the soluble receptor of interleukin-2. Int 7 Clin Lab Res 1996;26:207-10.

25 Abraham SN, Malaviya R. Mast cells in infection and mmunity. Infect Immun 1997;65:3501-8.

26 Bechi P, Dei R, Di Bello MG, et al. Helicobacter pylori potentiates histamine release from serosal rat mast cells in vitro. Dig Dis Sci 1993;38:944-9.

27 Kurose I, Granger DN, Evans DJ, et al. Helicobacter pyloriinduced microvascular protein leakage in rats: role of neutrophils, mast cells, and platelets. Gastroenterology 1994; 107:70-9.

28 Nakajima S, Krishnan B, Ota $\mathrm{H}$, et al. Mast cell involvement in gastritis with or without Helicobacter pylori infection. Gastroenterology 1997;113:746-54. 
29 Plebani M, Di Mario F, Dal Santo PG, et al. Measurement of pepsinogen group I in endoscopic gastroduodenal biopsies. Clin Chem 1990;36:682-4.

30 Dixon MF, Genta RM, Yardley JH, et al. Classification and grading of gastritis. The updated Sydney system. Am f Surg Pathol 1996;20:1161-8

31 Basso D, Navaglia F, Cassaro M, et al. Gastric juice polymerase chain reaction: an alternative to histology in the diagnosis of Helicobacter pylori infection. Helicobacter 1996;1:159-64.

32 Navaglia F, Basso D, Piva MG, et al. Helicobacter pylori cytotoxic genotype is associated with peptic ulcer and influences serology. Am $\mathcal{f}$ Gastroenterol 1 198;93:227-30.

33 Bradford MM. A rapid and sensitive method for the quantification of microgram quantities of protein utilizing the principle of protein-dye binding. Anal Biochem 1976;72: 248-54.
34 Plebani M, Basso D, Busatto G, et al. Are tryptase and cathepsin D related to Helicobacter pylori infection and mucosal

gastrin in peptic ulcer? Res Exp Med 1994;194:1-8.
35 Bechi P, Romagnoli P, Panula P, et al. Gastric mucosal histamine storing cells. Evidence for different roles of mast cells and enterochromaffin-like cells in humans. Dig Dis Sci 1995;40:2207-13.

36 Plebani M, Basso D, Busatto G, et al. Gastrin stimulates gastric mast cells in rabbits. Res Exp Med 1995;195:365-71.

37 Gillen D, El-Omar EM, Wirz AA, et al. The acid response to gastrin distinguishes duodenal ulcer patients from Helicobacter pylori-infected healthy subjects. Gastroenterology 1998;114:50-7.

38 Cairns JA, Walls AF. Mast cell tryptase is a mitogen for epithelial cells. Stimulation of IL-8 production and intercellular adhesion molecule-1 expression. F Immunol 1996;156: 275-83. 